\title{
Demographics, clinical disease characteristics, and quality of life in a large cohort of psoriasis patients with and without psoriatic arthritis
}

This article was published in the following Dove Press journal:

Clinical, Cosmetic and Investigational Dermatology

4 November 2015

Number of times this article has been viewed

\section{B Truongl,* \\ N Rich-Garg $2, *$ \\ BD Ehst' \\ AA Deodhar ${ }^{2}$ \\ $\mathrm{JH} \mathrm{Ku}{ }^{2}$ \\ K Vakil-Gilani ${ }^{2}$ \\ A Danve ${ }^{2}$ \\ A Blauvelt 1,3}

'Department of Dermatology, Oregon Health and Science University,

${ }^{2}$ Division of Arthritis and Rheumatic

Diseases, Oregon Health and Science University, ${ }^{3}$ Oregon Medical Research Center, Portland, OR, USA

*These authors contributed equally to this work
Correspondence: N Rich-Garg

Division of Arthritis and Rheumatic

Diseases (OP09), Department of

Medicine, Oregon Health

and Science University, 3|8| Southwest

Sam Jackson Park Road, Portland, OR

97239, USA

$\mathrm{Tel}+\mathrm{I} 5034948963$

Fax + I 5034941022

Email gargn@ohsu.edu
Innovation: What is already known about the topic: psoriasis ( $\mathrm{PsO})$ is a common skin disease with major impact on quality of life (QoL). Patient-reported data on QoL from large number of $\mathrm{PsO}$ patients with and without psoriatic arthritis (PsA) are limited. What this study adds: In a large cohort referred to a university psoriasis center, patients with $\mathrm{PsO}$ and concomitant PsA $(\sim 30 \%$ in this group) had greater degrees of skin and nail involvement and experienced greater negative impacts on QoL. Despite large numbers of patients with moderate-to-severe disease, use of systemic therapy by community practitioners was uncommon.

Background: PsO and PsA are common diseases that have marked adverse impacts on QoL. The disease features and patient-reported QoL data comparing PsO and PsA patients are limited.

Objective: To identify and compare demographics, clinical disease characteristics, and QoL scores in a large cohort of PsO patients with and without PsA.

Methods: All PsO patients seen in a psoriasis specialty clinic, named the Center of Excellence for Psoriasis and Psoriatic Arthritis, were enrolled in an observational cohort. Demographic, QoL, and clinical data were collected from patient-reported questionnaires and from physical examinations performed by Center of Excellence for Psoriasis and Psoriatic Arthritis dermatologists and a rheumatologists. Cross sectional descriptive data were collected and comparisons between patients with $\mathrm{PsO}$ alone and those with concomitant PsA are presented.

Results: A total of 568 patients were enrolled in the database. Mean age of PsO onset was 28 years and mean disease duration was 18 years. Those with family history had an earlier onset of $\mathrm{PsO}$ by $\sim 7$ years. Mean body surface area involvement with $\mathrm{PsO}$ was $14 \%$. Mean body mass index was 30.7. Prevalence of PsA was $29.8 \%$. PsA patients had a higher mean body surface area compared to patients with $\mathrm{PsO}$ alone $(16.7 \%$ vs $13.4 \%, P<0.05)$, higher prevalence of psoriatic nail changes $(54.4 \%$ vs $36 \%, P<0.0002)$, and worse QoL scores as assessed by the Short Form-12 (67 vs 52, $P<0.00001$ ), Psoriasis Quality of Life-12 questionnaire (62 vs 71, $P<0.01$ ), and Routine Assessment of Patient Index Data 3 (2.3 vs 4.7, $P<0.01$ ). Strikingly, $49 \%$ of patients with $\mathrm{PsO}$ had never received any systemic therapy.

Conclusion: These data highlight that PsO has marked negative impacts on QoL, while those patients with concomitant PsA are affected to a much greater degree. Despite large numbers of patients presenting with moderate-to-severe disease, use of systemic therapy for both $\mathrm{PsO}$ and PsA was uncommon.

Keywords: psoriasis, psoriatic arthritis, epidemiology, treatments, quality of life, patientreported outcomes

\section{Introduction}

Psoriasis ( $\mathrm{PsO})$ is a systemic inflammatory disease with prominent skin and joint manifestations; psoriatic arthritis (PsA), an inflammatory arthritis, affects up to $30 \%$ of $\mathrm{PsO}$ patients. ${ }^{1-3} \mathrm{PsO}$ and $\mathrm{Ps} \mathrm{A}$ negatively impact quality of life (QoL) and increases 
morbidity, and likely mortality, in patients afflicted with these diseases. ${ }^{3}$ Valuable information on these diseases has been learned from large disease-specific cohorts, such as those reported from Toronto and Boston. ${ }^{3,4}$ Here, we describe clinical data from the Center of Excellence for Psoriasis and Psoriatic Arthritis (CEPPA), a specialized multidisciplinary clinic at Oregon Health and Science University (OHSU) in Portland started in November 2006. CEPPA consists of dermatologists and rheumatologists with a special interest in $\mathrm{PsO}$ and $\mathrm{PsA}$, with the primary aim to provide comprehensive and multidisciplinary care to patients with these diseases. In addition, CEPPA collects and maintains a prospective sociodemographic and clinical database with the aim to better understand $\mathrm{PsO}$ and PsA and its impact on patients' lives. Here, we describe cross sectional data regarding demographics, clinical disease characteristics, and QoL data over the course of the first 4 years of CEPPA. These data highlight the disease burden of untreated PsO and PsA in the US.

\section{Methods}

\section{Study design}

This is an observational study of the PsO patients. All PsO patients seen in the CEPPA clinic were enrolled in an observational cohort. Cross sectional data from baseline evaluations is presented in this paper. This consists of patient-reported data collected at enrollment and chart review data from the first dermatology and rheumatology visits.

\section{Study population and setting}

Eligible patients were all adults over the age of 18 with $\mathrm{PsO}$ seen in the CEPPA dermatology clinic from November 1, 2006 to August 31, 2010. Patients were referred from primary care and dermatology providers from the states of Oregon and southwest Washington. Approval from the OHSU Institutional Review Board was obtained prior to enrollment. All subjects provided informed written consent to participate in the study. All patients with a confirmed diagnosis of PsO by CEPPA dermatologists were enrolled in the cohort. Based on clinical suspicion of PsA by dermatologists, patients were referred to a CEPPA rheumatologist; diagnosis of PsA was made after history and clinical evaluations, with laboratory markers and diagnostic imaging being utilized when necessary. At the rheumatology clinic assessment, patients were classified into the following categories: asymmetric oligoarthritis, polyarthritis, spondylitis, arthritis mutilans, arthritis limited to distal interphalangeal joint only, enthesitis, dactylitis, or a combination of these.

\section{Data collection}

We collected extensive patient-reported data by using a CEPPA questionnaire and exhaustive review of electronic medical records. This questionnaire included $\sim 400$ questions regarding demographics, extent of $\mathrm{PsO}$ and arthritis severity, psychosocial factors, QoL measures (see later), comorbidities, social habits, as well as queries on current and past medication use (Supplementary material). Study data were collected and managed using Research Electronic Data Capture (REDCap) hosted at OHSU. ${ }^{5}$ REDCap is a secure, web-based application designed to support electronic data capture for research studies.

\section{QoL measurements}

QoL was measured with validated instruments: Short Form-12 (SF-12), Psoriasis Quality of Life-12 questionnaire (PQOL-12), and the Routine Assessment of Patient Index Data 3 (RAPID3) form. ${ }^{6-8}$ The SF-12 is derived from the SF-36, which was developed in 1996 and revised in 2000 , to assess individual health perception. ${ }^{6}$ The PQOL-12 represents a 12-item self-administered, diseasespecific psychometric instrument created to assess QoL issues relevant to $\mathrm{PsO}$ patients. ${ }^{7}$ RAPID3 includes three patient-reported core data pieces that measure physical function, pain, and patients' global estimate of their disease. $^{8}$

\section{Data sources}

Data were collected from self-reported patient questionnaire and from electronic medical records. Data regarding QoL, joint symptoms, onset of $\mathrm{PsO}$ and joint symptoms, and age at diagnosis of $\mathrm{PsO}$, body regions (Supplementary material) affected by $\mathrm{PsO}$, use of tobacco and alcohol, family history, factors affecting $\mathrm{PsO}$ and joint symptoms, subjective effect of medications used, emotional factors, and data regarding employment and disability were collected from self-reported questionnaires. Medication use and comorbidities data were reconciled between self-reported and that retrieved from chart review. Data regarding $\mathrm{PsO}$ including nail changes and body surface area (BSA) were collected from dermatology chart notes. Data regarding arthritis, such as history of joint pain, presence or absence of arthritis, type of arthritis, age at onset of joint symptoms, and age of diagnosis with PsA, were collected from rheumatology chart notes. Demographic data, including age, vital signs, body mass index (BMI), laboratory tests, and imaging data, were collected from electronic medical records. 


\section{Bias}

Data from patients referred to a tertiary care referral center could suffer from referral bias, because patients with more severe psoriatic disease could be potentially overrepresented when compared to patients seen in the community. Patient-reported data suffers from potential for recall bias. Reconciliation regarding medication usage and comorbidities was made by review of medical records to reduce this bias.

\section{Sample size}

Formal sample size calculations were not performed due to the observational nature of the study.

\section{Statistical analyses}

Statistical analyses were performed using Stata Version 11.0 (StataCorp LP, College Station, TX, USA). Descriptive analyses were performed using means for continuous variables and proportions for categorical variables. The $t$-tests using two samples were performed for comparison of parametric data and Mann-Whitney $U$ test (Wilcoxon rank sum test) was used for nonparametric data. Categorical variables were compared using two sample proportion tests. Differences were considered statistically significant at $P$-values $<0.05$. Missing data were excluded from calculations.

\section{Results}

\section{Patient population}

A total of 598 PsO patients were seen in the CEPPA dermatology clinic from November 1, 2006 to August 31, 2010. Of these, 30 patients were subsequently lost to follow-up. The CEPPA rheumatologist evaluated 250 patients. The prevalence of PsA in this cohort of $\mathrm{PsO}$ patients was $29.8 \%$.

\section{Demographics}

The mean age of patients was 46.4 years and women comprised $50 \%$ of the cohort (Table 1). Caucasians represented the majority of the population (90.3\%). The mean BMI was $30.7 \mathrm{~kg} / \mathrm{m}^{2}$; $32.5 \%$ of patients were overweight ( $30>\mathrm{BMI} \geq 25 \mathrm{~kg} / \mathrm{m}^{2}$ ), $18.9 \%$ were obese $\left(35>\mathrm{BMI} \geq 30 \mathrm{~kg} / \mathrm{m}^{2}\right)$, and as much as $25.5 \%$ were morbidly obese (BMI $\left.\geq 35 \mathrm{~kg} / \mathrm{m}^{2}\right)$. Mean BMI for patients with PsA and with $\mathrm{PsO}$ alone were $31.4 \mathrm{~kg} / \mathrm{m}^{2}$ and $30.4 \mathrm{~kg} / \mathrm{m}^{2}$, respectively $(P=0.2)$. Family history of PsO

Table I Demographic and clinical characteristics of patients evaluated in the CEPPA clinic

\begin{tabular}{|c|c|c|c|c|}
\hline & $\begin{array}{l}\text { All patients }(N=568) \\
N \text {, mean }(S D) \text { or } N(\%)\end{array}$ & $\begin{array}{l}\text { Patients with PsA (N=169), } \\
N \text {, mean (SD) or } N(\%)\end{array}$ & $\begin{array}{l}\text { Patients without PsA (N=399), } \\
N \text {, mean (SD) or } N(\%)\end{array}$ & $P$-value ${ }^{a}$ \\
\hline Age at initial visit, years & $46.4(15.4)$ & $26.3(14.3)$ & $28.49(17.8)$ & 0.84 \\
\hline Female & $314(55.8 \%)$ & $84(50.3 \%)$ & $230(58.1 \%)$ & 0.09 \\
\hline Caucasians & $419(90.3 \%)$ & $125(91.9 \%)$ & $294(89.6 \%)$ & 0.45 \\
\hline Current smoker & $104(19.1 \%)$ & $33(20.8 \%)$ & 71 (I8.4\%) & 0.53 \\
\hline Current alcohol user & $391(72 \%)$ & $109(69 \%)$ & $282(73.3 \%)$ & 0.32 \\
\hline Family history of $\mathrm{PsO}$ & $259(53.5 \%)$ & $84(57.5 \%)$ & $175(51.8 \%)$ & 0.65 \\
\hline $\mathrm{BMI}, \mathrm{kg} / \mathrm{m}^{2}$ & $30.7(7.9), \mathrm{N}=459$ & $31.4(7.7)$ & $30.4(8)$ & 0.20 \\
\hline Age at onset of psoriasis, years & $27.8(16.8)$ & $26.3(14.3)$ & $28.5(17.8)$ & 0.18 \\
\hline Duration of $\mathrm{PsO}$, years & $18.5(14.3)$ & $20.2(14.2)$ & $17.7(14)$ & $0.07^{\mathrm{b}}$ \\
\hline BSA \% & 14.4 (18.7), N=494 & $16.7(21.3)$ & $13.4(17.4)$ & 0.05 \\
\hline Age at onset of joint pain, years & $37.5(12.4)$ & $37.5(12.4)$ & NA & NA \\
\hline $\begin{array}{l}\text { Time between onset of } \mathrm{PsO} \text { and joint } \\
\text { pain, years }\end{array}$ & II.I (II.8) & II.I (II.8) & NA & NA \\
\hline Duration of PsA, years & $7.75(7.9)$ & $7.75(7.9)$ & NA & NA \\
\hline Presence of psoriatic nail changes & $235(41.4 \%)$ & $92(54.4 \%)$ & $143(35.8 \%)$ & $<0.01$ \\
\hline SF-12 & $63.2(24.2)$ & $52.1(23.6)$ & $67.6(23)$ & $<0.01$ \\
\hline PQOL-12 & $64.5(33.3)$ & $70.8(34)$ & $61.8(32.7)$ & $<0.01$ \\
\hline RAPID3 & $2.7(2.3)$ & $3.6(2.3)$ & $2.3(2.1)$ & $<0.0 \mathrm{I}^{\mathrm{b}}$ \\
\hline Pain level today & $3.7(2.8)$ & $4.7(2.7)$ & $3.2(2.7)$ & $<0.0 \mathrm{I}^{\mathrm{b}}$ \\
\hline Are you currently employed? & $26 I(64.8 \%)$ & $78(67.2 \%)$ & $183(63.7 \%)$ & 0.51 \\
\hline Does PsO affect your ability to work? & $209(42.7 \%)$ & $103(67.7 \%)$ & $106(31.5 \%)$ & $<0.01$ \\
\hline Are you on disability? & $62(12.4 \%)$ & 30 (19.6\%) & $32(9.2 \%)$ & 0.01 \\
\hline
\end{tabular}


was reported by $45.3 \%$. Current alcohol and tobacco use was reported by $72 \%$ and $19 \%$, respectively.

\section{Disease characteristics}

The mean age at $\mathrm{PsO}$ onset as reported by the patients was 27.8 years, mean disease duration was 18 years with a patientreported mean delay from onset of symptoms to diagnosis of 3 years. The mean age of $\mathrm{PsO}$ onset for patients with a family history of $\mathrm{PsO}$ was 24 years, 7 years earlier than those without a family history. The mean BSA affected with PsO was $14.4 \%$ in the entire cohort. On the initial visit, $20 \%, 42 \%, 16 \%$, and $20 \%$ of patients had BSA involvement of $<3 \%, 3 \%-10 \%$, $11 \%-20 \%$, and $>20 \%$, respectively. On dermatologic examination, $41.4 \%$ of patients had psoriatic nail changes (including pitting, oil spots, dystrophy, and/or onycholysis).

The areas of $\mathrm{PsO}$ involvement as reported by the patients included the following: extremities (81\%); scalp (79\%); elbows and knees (77\%); face, ears, trunk, and buttocks (54\%-67\%); perianal (43\%); and palms, soles, underarms, and in folds (24\%-35\%). Predominantly palmoplantar PsO was seen in $12.9 \%$ and $16.7 \%$ of patients reported a history of guttate-like lesions either exclusively or in combination with larger plaques.

Eighty-five percent of patients reported known triggers of $\mathrm{PsO}$ exacerbation including stress $(94.7 \%)$, winter season (91\%), skin trauma $(71.5 \%)$, and summer season $(28 \%)$. Patients reported improvements in $\mathrm{PsO}$ with treatment (92.9\%), summer season (84.5\%), and pregnancy (18.7\%); $59.6 \%$ of patients reported spontaneous improvements in skin disease at times that were not due to any specific factors.

\section{Joint symptoms and PsA}

More than half of patients reported joint symptoms in the form of joint pain $(55.2 \%)$ or stiffness (57\%). In these patients, the most common sites of joint pain were the hands (89\%), spine, shoulders, and knees ( $85 \%$ for each of the last three). Among those diagnosed with PsA, mean duration of joint pain was 7.7 years. Of those diagnosed with PsA, the majority (91.1\%) was diagnosed on the initial rheumatology consultation and $18.3 \%$ were diagnosed based on history alone in the absence of any physical signs. Additional tests (laboratories or X-rays) were obtained in only $8.9 \%$ of patients and mostly consisted of sacroiliac joint X-rays to confirm sacroiliitis. Diagnosis of peripheral arthritis, including dactylitis and enthesitis, was made in all instances without obtaining radiographs. Figure 1 shows the distribution of PsA patterns; the most common was mixed type $(34.7 \%)$, followed by polyarthritis $(25.3 \%)$, and oligoarthritis $(11.8 \%)$. The prevalence of sacroiliitis or axial disease was $8.8 \%$, enthesitis or tendonitis was $2.9 \%$,

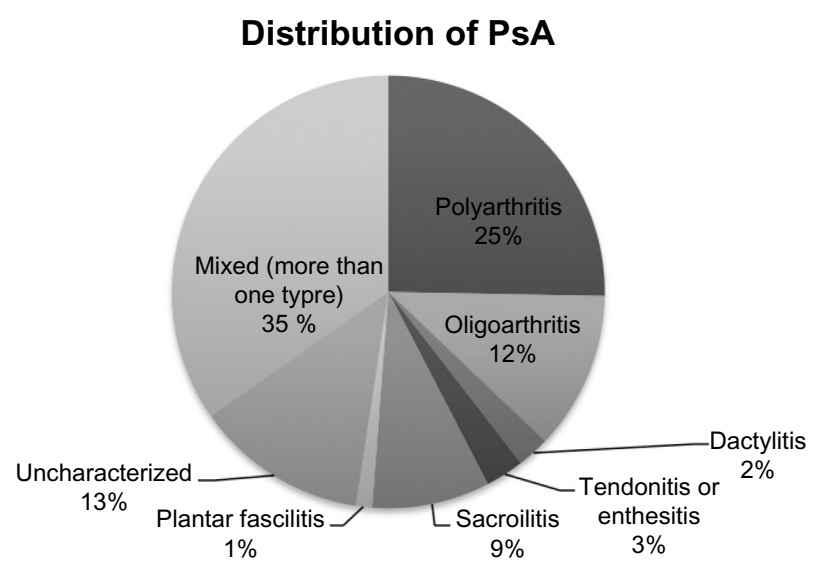

Figure I Distribution of psoriatic types among I69 PsA patients. Abbreviation: PsA, psoriatic arthritis.

dactylitis was $2.4 \%$, and plantar fasciitis was $1.2 \%$. No patient had arthritis mutilans.

\section{Relationship and comparison between patients with PsA and patients with $\mathrm{PsO}$ alone}

The mean time of onset of joint pain was 11 years $( \pm 11.8)$ after the onset of PsO. Four percent of patients developed joint pain before the onset of $\mathrm{PsO}, 26 \%$ within 1 year of onset of $\mathrm{PsO}, 76 \%$ within 20 years, and 94\% developed joint symptoms within 30 years of onset of PsO.

Age, race, sex, and history of alcohol use were not different between PsO and PsA (Table 1). Contrary to previous reports, ${ }^{9,10}$ smoking and family history were not found to be different in PsO patients with or without PsA. PsA patients had a higher mean BSA compared to patients with PsO alone (16.7\% vs $13.4 \%, P<0.05)$. Nail changes were more common in patients with PsA than PsO alone (54.4\% vs 36\%, $P<0.0002)$.

\section{Comorbidities}

Approximately one-fifth of $\mathrm{PsO}$ patients reported having hypertension (21.9\%) and obesity (20.4). Additionally, 10\% reported diabetes mellitus, a history of heart attack $(1.3 \%)$, congestive heart failure (1.2\%), inflammatory bowel disease $(1.2 \%)$, angina $(0.8 \%)$, and uveitis $(0.5 \%)$.

\section{Health-related QoL assessments}

Mean PQOL-12 and RAPID3 scores were 64.5 (where 0-47, 48-97, and 98-120 are considered low, moderate, and high severity, respectively) and 2.7 (where $<1,1-2,2-4$, and 4-10 are considered near remission, low, moderate, and high severity, respectively) suggesting at least a moderate disease activity for most patients (Table 1). ${ }^{11}$ Mean SF-12 
score (scale 0-100, where lower values signify worse QoL) was 63.2. Mean pain level reported on the day of interview was 3.7 on a visual analog scale of $0-10$ with 0 being no pain and 10 being the worst pain imaginable.

Compared to PsO-only patients, those with PsA had worse QoL scores as assessed by the SF-12 (67 vs 52, $P<0.00001$ ), where lower values signify worse QoL, and by the PQOL-12 (62 vs $71, P<0.01$ ) and RAPID3 (2.3 vs 4.7, $P<0.01$ ), where higher values signify worse QoL (Figure 2). More PsA patients reported difficulty in their ability to work compared to patients with $\mathrm{PsO}$ alone $(67 \%$ vs $31 \%, P<0.01)$ and more PsA patients were on disability ( $19.6 \%$ vs $9.2 \%, P<0.001)$.

Overall, rate of unemployment was $35 \%$, and $12.3 \%$ of the patients reported that they were currently receiving social security benefits. Of the 62 patients receiving social security benefits due to disability, the most common reason reported for being disabled was joint symptoms and arthritis (2.6\%); the remainder was due to fibromyalgia, mental disorders, and others. Thirty-one percent of patients reported that PsA affected their ability to work.

\section{Emotional factors}

Over one-fifth of $\mathrm{PsO}$ patients (23.8\%) reported being told by a health care professional that they have depression, $14.4 \%$ reported anxiety, and $40.8 \%$ patients were prescribed an antidepressant. Self-reported prevalence of bipolar disorder, post traumatic stress disorder (PTSD), and schizophrenia or schizoaffective disorder was $3.9 \%, 6 \%$, and $0.9 \%$, respectively. In terms of sleep quality, patients reported average sleep score of 4 out of 7 on a scale of 0 to 7 , where 0 is very poor sleep and 7 signifying "sleeping like a baby". In terms of stress level, patients reported elevated stress ( 4.5 out of 7 , with 0 as no stress and 7 as extremely high stress).

\section{Treatment patterns}

Based on patient-reported data of past treatments at the first CEPPA visit, few patients were receiving treatment with disease-modifying antirheumatic drugs. Forty-nine percent of patients with $\mathrm{PsO}$ alone and $10 \%$ of patients with PsA had never received systemic therapy with oral or biologic medications, and only $10 \%$ and $12 \%$ of patients with $\mathrm{PsO}$ and PsA, respectively, were on systemic therapies at the time of enrollment. Conversely, nearly all (97\%) patients had received topical corticosteroids during their lifetime, whereas $40 \%$ reported using topical tar in the past and $\sim 20 \%$ of patients had used topical retinoids. Approximately $26 \%$ of the patients had used phototherapy. Only $11 \%$ of patients reported receiving methotrexate or a biologic agent for either $\mathrm{PsO}$ or PsA at the time of the enrollment. Of those who had received systemic therapy, methotrexate (30\% patients) and etanercept (19\% patients) were the most commonly used drugs, followed by infliximab and adalimumab $(8.6 \%$ patients each). Further, $63 \%-68 \%$ of patients who received methotrexate or cyclosporine and $78 \%-83 \%$ of those who received an antitumor necrosis factor drug noted some or significant therapeutic benefit (Table 2).

\section{Discussion}

In this study, we describe a new large cohort of PsO and PsA patients seen at a tertiary care academic center over 4 years. A number of interesting findings were gleaned from our analyses, including new data on the clinical relationship between patients with $\mathrm{PsO}$ alone and those with concomitant PsA. Among PsO patients, the reported prevalence of PsA ranges from $20 \%$ to $40 \% .{ }^{12,13}$ In our cohort of $\mathrm{PsO}$ patients, the prevalence of PsA was 29.8\%. Interestingly, a much higher percentage of patients reported joint pain and stiffness (ie, $>50 \%$ ), emphasizing that not all arthralgias and arthritis in the setting of PsO is PsA. As previously described, most of our patients had the onset of PsA following or concomitantly with the onset of PsO. The type of PsA was predominantly of mixed clinical nature, eg, enthesitis plus oligoarthritis. This finding highlights the fact that PsA is often heterogeneous in nature, and less commonly restricted to one particular clinical
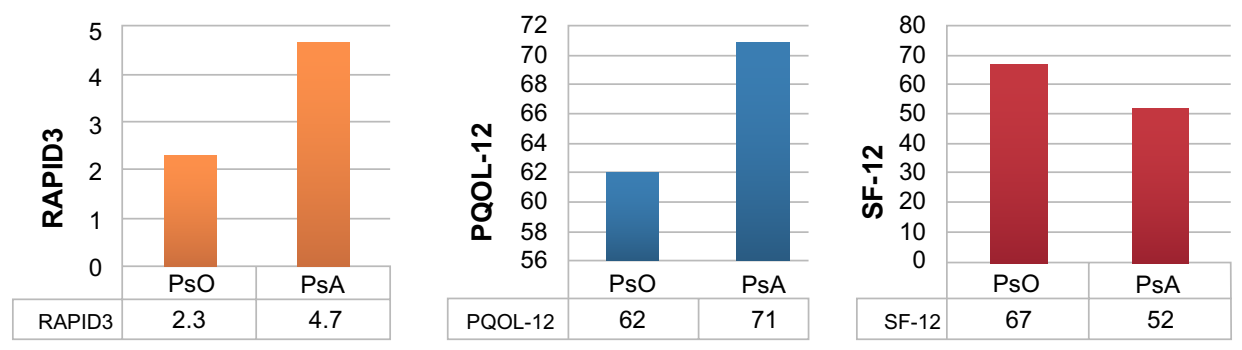

Figure 2 Disease activity and quality of life indices in patients with PsO only and those with both PsO and PsA.

Abbreviations: PQOL-12, Psoriasis Quality of Life-12 questionnaire; PsA, psoriatic arthritis; PsO, psoriasis; RAPID3, Routine Assessment of Patient Index Data 3; SF-I2, Short Form- 12. 
Table 2 Patient-reported treatments for psoriasis, $\mathrm{N}=568$

\begin{tabular}{|c|c|c|c|c|c|c|c|c|}
\hline & \multirow{2}{*}{$\begin{array}{l}\text { Current } \\
\text { use, N (\%) }\end{array}$} & \multirow{2}{*}{$\begin{array}{l}\text { Past use, } \\
\text { N (\%) }\end{array}$} & \multirow{2}{*}{$\begin{array}{l}\text { Never } \\
\text { used, } \\
\text { N (\%) }\end{array}$} & \multirow{2}{*}{$\begin{array}{l}\text { Duration of } \\
\text { use, median } \\
\text { (IQR), } \\
\text { month }\end{array}$} & \multicolumn{3}{|c|}{ Perceived benefit, N (\%) } & \multirow{2}{*}{$\begin{array}{l}\text { Perceived side effects } \\
\text { (percentage of those } \\
\text { that had ever taken } \\
\text { medications) }\end{array}$} \\
\hline & & & & & A lot & Some & Not at all & \\
\hline Tar anthralin & $65(11.44)$ & $167(29.4)$ & $336(59.1)$ & $43.7(87.1)$ & $17(8.3)$ & $109(53.2)$ & $79(38.5)$ & $14(6)$ \\
\hline Topical steroids & $326(57.4)$ & $168(29.6)$ & $74(13)$ & $61.7(92.7)$ & $58(14.7)$ & $285(72.2)$ & $52(13.2)$ & $47(9.5)$ \\
\hline Topical retinoids & $22(3.8)$ & $100(17.61)$ & $446(78.5)$ & 34 (7।.2) & $3(3.5)$ & $52(6 \mid .2)$ & $30(35.3)$ & $8(6.6)$ \\
\hline Ultraviolet (UV) light & $19(3.4)$ & $129(22.71)$ & $420(73.9)$ & $28.6(65.6)$ & $29(24.6)$ & $62(52.5)$ & $27(22.9)$ & $14(9.5)$ \\
\hline Narrowband UVB & $10(1.8)$ & $55(9.7)$ & $503(88.6)$ & $19.2(34)$ & $23(41.8)$ & $22(40)$ & $10(18.2)$ & $6(9.2)$ \\
\hline PUVA & $4(0.7)$ & $61(10.7)$ & $503(88.6)$ & $24.3(35.1)$ & $24(45.3)$ & $18(34)$ & II (20.8) & $13(20)$ \\
\hline Grenz ray & 0 & $36(6.3)$ & $532(93.7)$ & $2.8(3.1)$ & II (36.7) & $9(30)$ & $10(33.3)$ & 0 \\
\hline Excimer laser & $\mathrm{I}(0.2)$ & $10(1.8)$ & $557(98.1)$ & $2.8(1.9)$ & $4(50)$ & $3(37.5)$ & I (12.5) & $2(18.2)$ \\
\hline Oral retinoids & $10(1.8)$ & $4 \mid(7.2)$ & $517(91)$ & $20(2 I . I)$ & II (26.2) & $21(50)$ & $10(23.8)$ & I5 (29.4) \\
\hline Methotrexate & $66(11.6)$ & $109(19.2)$ & $393(69.2)$ & $29(59.8)$ & $4 \mid(28.7)$ & $56(39.2)$ & $46(32.2)$ & $42(24)$ \\
\hline Cyclosporine & $4(0.7)$ & $27(4.8)$ & $537(94.5)$ & $\mid 7.5(3 \mid .2)$ & $8(33.3)$ & $7(29.2)$ & $9(37.5)$ & $6(19.4)$ \\
\hline Adalimumab & $16(2.8)$ & $33(5.8)$ & $519(9 \mid .4)$ & $14(13.4)$ & 15 (34.9) & $19(44.2)$ & 9 (20.9) & $12(24.5)$ \\
\hline Etanercept & $32(5.6)$ & 79 (13.9) & $457(80.5)$ & I7.8(I7.6) & $38(40.4)$ & $38(40.4)$ & $18(19.2)$ & $23(20.7)$ \\
\hline Infliximab & 21 (3.7) & $28(4.9)$ & 519 (91.4) & $13.8(\mid 4.1)$ & 14 (35.9) & 19 (48.7) & $6(15.4)$ & $10(20.4)$ \\
\hline Ustekinumab & $\mathrm{I}(0.2)$ & $2(0.4)$ & $565(99.5)$ & $22(9.2)$ & I (33.3) & $2(66.7)$ & 0 & 0 \\
\hline Golimumab & 0 & $\mathrm{I}(0.2)$ & $567(99.8)$ & NA & 0 & 0 & 0 & 0 \\
\hline
\end{tabular}

Abbreviations: IQR, interquartile range; N, number of patients; NA, no data available; PUVA, psoralen combined with ultraviolet A; UVB, ultraviolet B.

phenotype as often taught. Recognition of all the various clinical forms that PsA may take is therefore important in proper diagnosis. More extensive skin disease was associated with higher prevalence of PsA, which has also been seen in previous studies. ${ }^{1,14}$ Lastly, nail disease was more frequent in those with PsA compared to PsO patients with PsA. In particular for these last two points, recognition of more severe skin disease and/or psoriatic nail disease in their $\mathrm{PsO}$ patients should prompt dermatologists to inquire further on the signs and symptoms of PsA.

The percentage of morbidly obese patients (11\%) in our cohort was much higher compared to the general population $(6.3 \%){ }^{15}$ PsA patients had higher BMI than patients with $\mathrm{PsO}$ alone. An association between $\mathrm{PsO}$ and obesity has been reported. As well, obese psoriatics are often more difficult to treat for a variety of reasons. ${ }^{16}$ Because of excess weight, risks are also increased for cardiovascular disease and osteoarthritis. ${ }^{16}$ Thus, weight loss should continue to be an important goal for obese patients with PsO and PsA.

We did not find any correlations between smoking and PsA, despite previous reports suggesting that PsA is less frequent among smokers. ${ }^{9}{ }^{10}$ The true relationship between smoking and PsA may not yet be known. The relationship between family history and development of PsO and PsA is well known as evidenced by its inclusion as one of the CASPAR (ClASsification criteria for Psoriatic ARthritis) criterion for diagnosis of PsA. Our study demonstrates an earlier onset of PsA in patients with a family history of PsO. ${ }^{17}$ As expected, PsA patients were found to have worse
QoL than those with PsO alone. This is not surprising, since arthritis of any type has been shown to have significant negative impacts on health-related QoL. ${ }^{18,19}$ Indeed, identifying PsA in PsO patients seems particularly important in that the early diagnosis and treatment is likely to demonstrate significant benefits in terms of QoL. In addition, early treatment of PsA can prevent permanent joint damage, especially with tumor necrosis factor inhibitor use. Lastly, identification of PsA in PsO patients should lead to the selection of therapies more specifically designed to help both conditions.

We have several limitations. Our data is a single-center study that lacks a control group and is limited by factors associated with patient-reported surveys, including potential recall bias, missing data, and subjectivity of interpretation of self-reported data. As well, patients were referred from community clinics to our university center, which may lead to a referral bias, ie, preferentially more patients with severe disease being referred.

Despite these limitations, there were significant notable findings. In our cohort of referred patients with average disease duration of 21 years, a large number of patients were likely undertreated for both $\mathrm{PsO}$ and PsA, especially given that the mean BSA of our cohort was $14.4 \%, 43 \%$ had BSA values of $10 \%$ or more, and nearly a quarter of patients had concomitant PsA. Armstrong et al have recently highlighted the problem of nontreatment and undertreatment of $\mathrm{PsO}$ within the medical community, pointing to a number of factors that contribute to this problem. ${ }^{20}$ Some of these include 
the following: 1) misperceptions by patients and physicians that $\mathrm{PsO}$ is not a serious disease; 2) overemphasis of potential side effects by patients and physicians; 3) physicians who fail to prescribe systemic medications due to lack of training; 4) misperceptions that prescribing systemic therapies causes inordinate administrative burdens; and 5) high cost of therapies that leads to restrictive barriers by insurance and health care systems to limit utilization. In future reports, we plan to describe the many positive benefits gained from treating patients at CEPPA, many of whom were treated for the first time with systemic therapies.

\section{Funding}

There was no funding source for conducting this study.

\section{Disclosure}

Dr A Blauvelt is a clinical investigator and scientific consultant for AbbVie, Amgen, Anacor, Boehringer Ingelheim, Celgene, Janssen, Lilly, Merck, Novartis, Pfizer, and Sandoz. Dr AA Deodhar has a research grant and is a consultant for AbbVie, Amgen, Janssen, Novartis, Pfizer, and UCB. Dr BD Ehst has a research grant and is a consultant for AbbVie, Amgen, Janssen, Celgene, Pfizer, Merck, and Lilly. All the other authors declare no conflicts of interest in this work.

\section{References}

1. Gelfand J, Gladman D, Mease P. Epidemiology of psoriatic arthritis in the population of the United States. J Am Acad Dermatol. 2005;53(57): e1-e13.

2. Feldman S, Fleischer AJ, Cooper J. New topical treatments change the pattern of treatment of psoriasis: dermatologists remain the primary providers of this care. Int J Dermatol. 2000;39:41-44.

3. Gladman D, Schentag C, Tom B. Development and initial validation of a screening questionnaire for psoriatic arthritis: the Toronto psoriatic arthritis screen (ToPAS). Ann Rheum Dis. 2009;68:497-501.

4. Husni M, Meyer K, Cohen D. The PASE questionnaire: pilot-testing a psoriatic arthritis screening and evaluation tool. J Am Acad Dermatol. 2007;57:481-487.

5. Harris P, Taylor R, Thielke R, Payne J, Gonzalez N, Conde J. Research electronic data capture (REDCap) - a metadata-driven methodology and workflow process for providing translational research informatics support. J Biomed Inform. 2009;42(2):377-381.
6. Grozdev I, Kast D, Cao L. Physical and mental impact of psoriasis severity as measured by the compact short form-12 health survey (SF-12) quality of life tool. J Invest Dermatol. 2012;132(4):1111-1116.

7. Koo J, Menter A, Lebwohl M. The relationship between quality of life and disease severity: results from a large cohort of mild, moderate and severe psoriasis patients. Br J Dermatol. 2002;147:1077-1079.

8. Pincus T, Bergman M, Yazici Y. RAPID3 - an index of physical function, pain, and global status as "Vital signs" to improve care for people with chronic rheumatic diseases. Bull NYU Hosp Jt Dis. 2009;67(2): 211-225.

9. Naldi L, Parazzini F, Brevi A. Family history, smoking habits, alcohol consumption and risk of psoriasis. Br J Dermatol. 1992;127(3): 212-217.

10. Eder L, Shanmugarajah S, Thavaneswaran A. The association between smoking and the development of psoriatic arthritis among psoriasis patients. Ann Rheum Dis. 2012;71(2):219-224.

11. Pincus T, Swearingen C, Bergman M, Yazici Y. RAPID3 (routine assessment of patient index data 3), a rheumatoid arthritis index without formal joint counts for routine care: proposed severity categories compared to disease activity score and clinical disease activity index categories. J Rheumatol. 2008;35(11):2136-2147.

12. Gladman D. Psoriatic arthritis. Dermatol Ther. 2004;17:350-363.

13. Gladman D, Antoni C, Mease P, Clegg D, Nash P. Psoriatic arthritis: epidemiology, clinical features, course, and outcome. Ann Rheum Dis. 2005;64:ii14-ii17.

14. Eder L, Chandran V, Shen H, et al. Incidence of arthritis in a prospective cohort of psoriasis patients. Arthritis Care Res. 2011;63(4): 619-622.

15. Ogden C, Carroll MD, Kit B, Flegal K. Prevalence of overweight, obesity, extreme obesity among adults: United States, trends 1960-1962 through 2009-2010. NHANES. 2012;82.

16. Bremmer S, Van Voorhees AS, Hsu S, et al; National Psoriasis Foundation. Obesity and psoriasis: from the medical board of the national psoriasis foundation. J Am Acad Dermatol. 2010;63(6):1058-1069.

17. Taylor W, Gladman D, Helliwell P, et. al. Classification criteria for psoriatic arthritis: development of a new criteria from a large international study. Arth. Rheum. 2006;54:2665-2673.

18. Husted J, Gladman D, Farewell N. Validating the SF-36 health survey questionnaire in patients with psoriatic arthritis. J Rheumatol. 1997;24: 511-517.

19. Zachariae H, Zachariae R, Blomqvist K. Quality of life and prevalence of arthritis reported by 5795 members of the nordic psoriasis associations. Data from the nordic quality of life study. Acta Derm Venereol. 2002;82: 108-113.

20. Armstrong A, Robertson A, Wu J, Schupp C, Lebwohl M. Undertreatment, treatment trends, and treatment dissatisfaction among patients with psoriasis and psoriatic arthritis in the united states: findings from the national psoriasis foundation surveys, 2003-2011. JAMA Dermatol. 2013;149(10):1180-1185.
Clinical, Cosmetic and Investigational Dermatology

\section{Publish your work in this journal}

Clinical, Cosmetic and Investigational Dermatology is an international, peer-reviewed, open access, online journal that focuses on the latest clinical and experimental research in all aspects of skin disease and cosmetic interventions. All areas of dermatology will be covered; contributions will be welcomed from all clinicians and

\section{Dovepress}

basic science researchers globally. This journal is indexed on CAS. The manuscript management system is completely online and includes a very quick and fair peer-review system, which is all easy to use. Visit http://www.dovepress.com/testimonials.php to read real quotes from published authors 